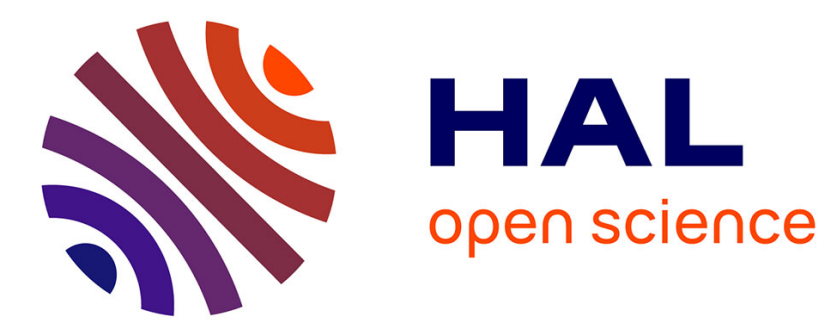

\title{
Connecting an architectural plant model to a forest stand dynamics model-application to Austrian black pine stand visualization
}

Feng, Reffye, Dreyfus, Auclair

\section{- To cite this version:}

Feng, Reffye, Dreyfus, Auclair. Connecting an architectural plant model to a forest stand dynamics model-application to Austrian black pine stand visualization. Annals of Forest Science, 2012, 69 (2), pp.245-255. 10.1007/s13595-011-0144-5 . hal-00930715

\section{HAL Id: hal-00930715 https://hal.science/hal-00930715}

Submitted on 1 Jan 2012

HAL is a multi-disciplinary open access archive for the deposit and dissemination of scientific research documents, whether they are published or not. The documents may come from teaching and research institutions in France or abroad, or from public or private research centers.
L'archive ouverte pluridisciplinaire HAL, est destinée au dépôt et à la diffusion de documents scientifiques de niveau recherche, publiés ou non, émanant des établissements d'enseignement et de recherche français ou étrangers, des laboratoires publics ou privés.

$$
\text { Copyright }
$$




\title{
Connecting an architectural plant model to a forest stand dynamics model-application to Austrian black pine stand visualization
}

\author{
Lu Feng • Philippe de Reffye • Philippe Dreyfus • \\ Daniel Auclair
}

Received: 10 March 2011 / Accepted: 22 September 2011 / Published online: 14 October 2011

(C) INRA and Springer-Verlag, France 2011

\begin{abstract}
- Context Forest stand dynamics models simulate the growth of trees in stands; based on field measurements and system knowledge, they provide a relatively precise representation of forest growth and are well adapted for forest management purposes. Architectural models describe the structure of plants according to ontogenetic development processes; as a support of biomass production and partitioning at organ scale, they simulate individual tree development.

- Aims The aim of this study was to link a stand dynamics model and an architectural model to simulate stand dynamics, in which the ecological or silvicultural modelling from the stand model and the architecture representation could be integrated, to provide individual tree details at the stand level.

- Methods Stand-level simulations of Austrian black pine dynamics provided global results on tree growth from the empirical forest growth model PNN, and branching details
\end{abstract}

\footnotetext{
Handling Editor: Gérard Nepveu

L. Feng $(\bowtie) \cdot$ P. de Reffye

UMR AMAP (botAnique et bioinforMatique

de l'Architecture des Plantes), CIRAD,

TA A-51/PS2, Bd. de la Lironde,

34398 Montpellier cedex 5, France

e-mail: fyafeng@gmail.com

P. Dreyfus

URFM, INRA,

84914 Avignon, France

D. Auclair

UMR AMAP, INRA,

34398 Montpellier, France
}

for individual trees were provided by the functionalstructural plant model (FSPM) GreenLab.

- Results Individual tree dynamics were computed, and the simulated trees were integrated at the stand level for visualizing two different management scenarios.

- Conclusion By combining a stand dynamics model adapted to forest management with an FSPM with detailed tree architecture, it is possible to simulate individual tree structure with consistent dimensions, adapted to ecological and silvicultural modelling for decision support in forest management.

Keywords Empirical forest growth model - Architectural model $\cdot$ GreenLab $\cdot$ Pinus nigra nigra $\cdot$ Visualization

\section{Introduction}

Forest growth and yield simulators are commonly used for decision support in forest management (Pretzsch 2009). Many different types of models have been developed, and several ways of classifying forest models can be found in the literature (e.g. Vanclay 1994; Pretzsch et al. 2008). Schematically, for predicting the effects of silvicultural management, forest stand models can be subdivided into empirical forest models (EFMs) and process-based models (PBMs). EFMs are mostly devoted to stand level production and tree size distribution, and are extensively used for forest management purposes. They are established on system knowledge, by which various ecological factors such as site conditions, stand structure, inter-plant competition or management scenarios can be taken into consideration. PBMs account for the major eco-physiological components of the system and the rates of transfer between 
components (photosynthesis, water balance, nutrient cycling). According to Kimmins et al. (2008), EFMs make "excellent" predictors under unchanging environmental conditions, whereas PBMs exhibit high flexibility under changing environment. The pros and cons of each have been addressed for example by Mäkelä et al. (2000) and Kimmins et al. (2008), who suggest combining these in "hybrid simulation models". With improvements in computer technology and progress in scientific knowledge concerning plant morphology, tree dynamics and competition within forest stands, new generations of models are being developed (Pretzsch et al. 2008; Muys et al. 2010). With increasing concern of forest managers, as well as other stakeholders, about sustainable ecosystem management and ecosystem services, it has become necessary to address a large scope of spatio-temporal scales. These extend upwards from forest stands to ecosystem or landscape level (Auclair 2010) and downwards to individual trees (King 2005), and such up- and downscaling entails increased complexity and uncertainty (Brugnach et al. 2008).

It is becoming increasingly important to take in account individual tree structure in forest management for different objectives, including for example carbon allocation and sequestration (Melson et al. 2011), fuel description for fire risk assessment (Parsons et al. 2011), stand or landscape visualization (Griffon et al. 2011) or for calibrating models for remote sensing applications (Castel et al. 2001; Biliouris et al. 2009).

The organization of individual plant components in space consists of topology (the physical connections between plant components) and geometry (the shape, size, orientation and spatial location of the components), which change during the development of the plants. Modelling individual trees requires accounting for their structure and can (but does not necessarily) involve physiological processes, leading to "functionalstructural plant models" (FSPMs). Such models are usually built on recursive equations with more or less detailed organ-level computation, depending on the needs for simulation of tree development (de Reffye and Houllier 1997; Perttunen et al. 1998; Yan et al. 2004; Vos et al. 2010). The description of tree structure commonly involves empirical geometric models (Collin et al. 2011; Côté et al. 2011) and seldom includes details of the ontogenetic developmental processes (Sterck and Schieving 2007). The latter are based on the concept of plant architecture, which was initiated in the 1970 s by Hallé and co-workers (1978) and followed by many indepth studies reviewed by Barthélémy and Caraglio (2007). Architectural analysis addresses both endogenous processes inherent to each species and exogenous constraints exerted by the environment.
FSPMs are considered as very relevant for modelling physiological processes, individual tree level biomass production and carbon partitioning into different compartments (Pretzsch et al. 2008), but the extension from individual tree to stand level can be extremely demanding on computing capacity and time. Despite the importance of detailed canopy description for many applications, forest stand simulators very rarely address individual tree structural details (Sievänen et al. 2008), mainly due to the high computing time required. Maintaining a high degree of structural detail when scaling up from organ level to stand (or landscape) remains an important challenge, as in general, the limitations of computer capacity require many simplifications in individual tree structure modelling (Kohyama et al. 2005). To address this challenge, tree structure can be simply represented by crown envelope shape (Rautiainen et al. 2008) or by using allometric relations (King 2005; West et al. 2009), fractals (Collin et al. 2011; Parsons et al. 2011), "numerical tree modelling" (Collin et al. 2011) or other geometric representations of tree architecture (Cescatti 1997; Perttunen et al. 1998; Biliouris et al. 2009). However, these simplifications can greatly affect the uncertainty of estimations, as has been shown by Melson et al. (2011) who cite differences up to $50 \%$ in volume and biomass according to differences in tree form.

To address the dilemma posed by the requirement for accurate, detailed estimations, at the stand or ecosystem level, with limited computer capacity, several authors have suggested coupling models at different scales, using a hierarchical approach (Mäkelä 2003). Jallas et al. (2009) added a 3-D architecture component to a plant simulation model for cotton, a "simple" plant; Renton et al. (2005) introduced architectural analysis in an L-system-based model, coupled with a canonical model of tree resource allocation, to simulate individual plant form and function for birch; Wang et al. (2006) used static computer-designed 3-D tree images together with an empirical growth model based on inventory data, for forest landscape visualization purposes. However, to our knowledge, the only example of coupling a detailed tree architectural model (sensu Hallé et al. 1978) with a forest stand dynamics model was that of Meredieu et al. (2004) who constrained AMAPsim architectural model parameters by outputs from a stand growth and yield model for Pinus pinaster.

The present work is a further attempt to benefit both from the high reliability and the high computing speed of an empirical forest model and from the high degree of detail of an architectural model, by combining two such models. As an example, two realistic silvicultural scenarios (thinned stand or unthinned control) were applied to Austrian black pine, simulated with the empirical forest model "PNN" (Dreyfus 1993). The results obtained through the simulator 
were then used to calibrate the Architectural component of the functional-structural plant model "GreenLab" (Yan et al. 2004), which in turn provided detailed individual tree architecture data. Among the various outputs of decision support tools, forest stand visualization is becoming increasingly important for stakeholder involvement and negotiation (Pretzsch et al. 2008; Muys et al. 2010). An application to visualization of the forest stands resulting from the two simulated scenarios is presented here.

\section{Materials and methods}

\subsection{Austrian black pine architecture}

According to Barthélémy and Caraglio (2007), a plant can be seen as a hierarchical branched system in which the axes can be grouped into categories according to their morphological, anatomical or functional distinctive features. Austrian black pine (Pinus nigra Arn. subsp. nigra) has a rhythmic ramification and growth; all axes are monopodial and branches are orthotropic. It belongs to Rauh's architectural model as described by Hallé et al. (1978), presented in Fig. 1a (from Barthélémy and Caraglio 2007). Black pine is monocyclic: the time step used to describe meristem development is 1 year, corresponding to one new growth unit (GU) that produces a whorl of branches along the stem (Fig. 1b). In Pinus, GUs are composed of a large number of very small internodes, but for computing requirements (see Section 3) we have considered the GU as the smallest entity to be represented, similarly to Wang et al. (2010). Barthélémy and Caraglio (2007) defined the "physiological age" (PA) of a meristem or of an elementary botanical entity, and in simple cases such as P. nigra nigra, the physiological age corresponds to the branching order. Black pine exhibits four branching orders, the stem being defined as order 1 . The number of branches on a whorl can vary, both with the position and the order of the axis, generally from 1 to 5 on the stem, and from 1 to 3 on higher-order axes (Castel et al. 2001).

\subsection{Field data}

The dataset used for calibration of the PNN growth model (individual size and increments, mortality) came from a network of 76 plots (46 plots in six thinning or precommercial thinning experiments +30 permanent yield plots), from regeneration stage to mature stands, within the Mediterranean range of this species in Southern France and covering various site conditions, initial stand structures and thinning characteristics. It contained ca. 25,750 diameter increments and 3,750 height increments on more than 13,000 trees; the stem density ranged from 200 to 18,000 stems per hectare, and the basal area from 1 to $64 \mathrm{~m}^{2} \mathrm{ha}^{-1}$, according to thinning treatments (from unthinned control to relative spacing values up to $100 \%$ ). For the branching model, the data were obtained from stem analyses performed on four trees per stand (dominant, codominant, average and suppressed) in a subset of eight stands from the above-mentioned network, with age ranging from 23 to 114 years, height from 5.3 to $27.0 \mathrm{~m}, d b h$ (stem diameter at $1.3 \mathrm{~m}$ height) from 7 to $45 \mathrm{~cm}$. More than 3,200 branches (dead/green) were measured for diameter, and 1,300 for angle and extents. Additional botanical data on black pine came from the observations of Castel et al. (2001).

\subsection{The empirical forest dynamics model PNN}

For P. nigra nigra, a tree-level distance-independent growth model (Dreyfus 1993) including sub-models predicting height and stem diameter growth, competition-induced mortality, stem volume, height to living crown and an allometric branching sub-model was calibrated, connected and embedded in a module of the Capsis simulation platform (http://www.inra.fr/capsis, Dufour-Kowalski et al. 2011), named "PNN". This module enables the simulation of the evolution of a black pine stand according to site
Fig. 1 a A simplified representation of Rauh's architectural model (from Barthélémy and Caraglio 2007); b detail of four successive growth units on the stem, showing branch whorls. The second stem GU with its whorl is presented in grey

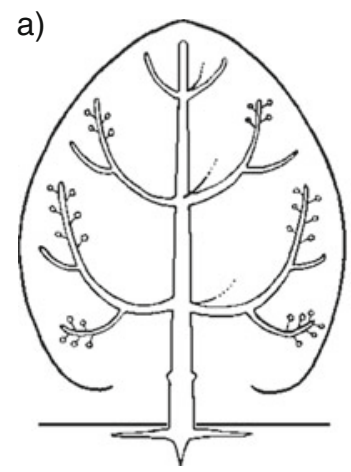

b)

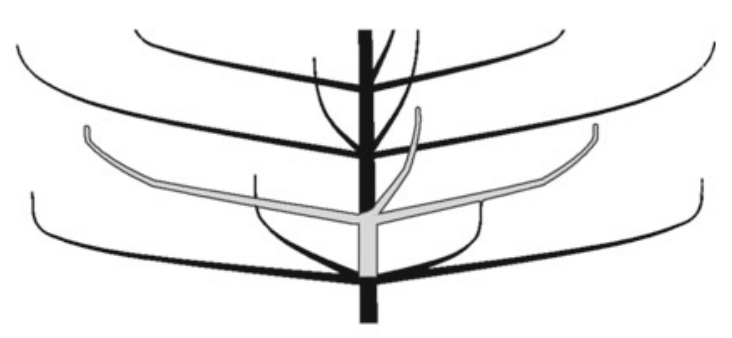


index and to competition controlled by thinning scenarios, from young stage (trees a few metres high and around 10 15 years old) to age 100 or more, with a 5 -year time step.

At each step, the outputs from PNN include usual stand characteristics (number of stems, basal area,...) and individual information (age, $d b h$, total height $H$, height to crown base $H c b$ ) for each tree. After validation, the growth model predictions have served, for example to define management guidelines in a new technical guide for forest managers (Ladier and Rey 2011).

Virtual tree coordinates were computed in the present study for visualization purposes (not used by the distanceindependent growth model). The branching sub-model provided additional individual tree outputs calculated at each time step for the trees remaining in the stand after thinning or natural mortality, concerning each whorl (whorl order from the bottom to the top of the tree, number of branches in the whorl). Within each whorl, the following characteristics of the main axis of each green branch were computed: height of insertion from the ground $(\mathrm{Br} H t)$, basal diameter $(D B)$, angle of insertion (Ins Ang), horizontal extent (Horiz Extent) and distance between origin and tip (Chord L, see Fig. 2; an example is shown in Table 1). As the branching model is

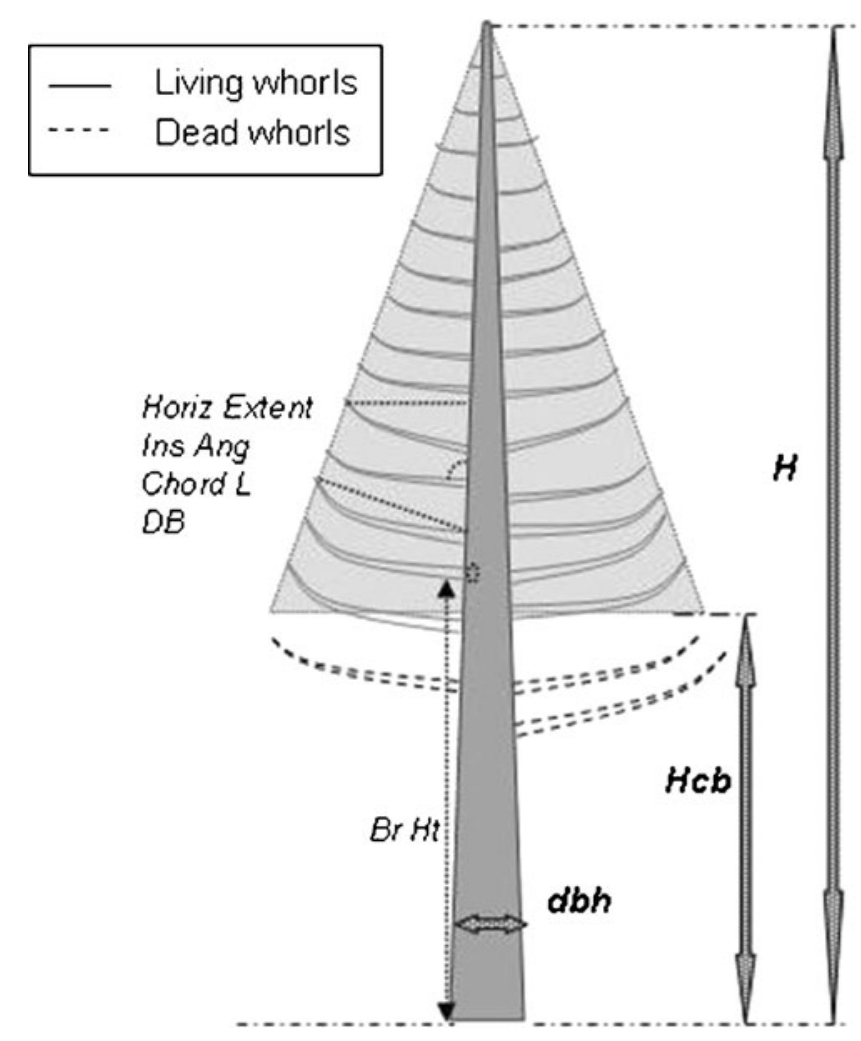

Fig. 2 Detail of individual tree variables from PNN: global tree variables (diameter at breast height $d b h$, height of crown basis $H c b$, total tree height $H$ ) and variables for each living whorl, corresponding to Table 1 (height of insertion $\mathrm{Br} H t$, base diameter $D B$, chord length Chord L, insertion angle Ins Ang and horizontal extent Horiz Extent) static (allometric relationships), the number of branches in each whorl and the characteristics of the corresponding branches were simulated at each simulation step, and there is no direct link between a branch at one step and a branch in the same whorl at the previous step.

\subsection{The functional-structural plant model GreenLab}

GreenLab provides a generic mathematical framework for functional-structural plant modelling, based on the botanical concepts of plant architecture (de Reffye et al. 1988); it has been described in detail by Yan et al. (2004). Organogenetic rules provide the plant structure, which can be defined as an interconnected network of organs, whereas source-sink relationships among these organs determine biomass production and allocation. A consistent time unit for architectural development and ecophysiological functioning is defined. This allows the discrete dynamic system of growth to be derived, and its state variables are sufficient to deduce the whole-plant architecture (Mathieu et al. 2009). The FSPM GreenLab has been validated for a large number of small cultivated plants (de Reffye 2009). A complete validation (for both structure and function) for mature trees is still under way, but the architectural component and particularly the visual aspects have been evaluated, mainly by expert knowledge, and are currently used for architecture and landscape planning purposes (http://www.bionatics.com/).

In the present study, we restricted the use of the model to plant structure (topology and geometry), without considering the physiological processes, as the growth of individual plants was driven by the outputs of PNN. Following Barthélémy and Caraglio (2007), each axis is composed of a succession of growth units, and the different categories of axes are characterized by the notion of PA. For black pine, four PAs are defined, each characterizing one of the four axis orders. As P. nigra is monocyclic, the number of growth units on the stem, $N_{1}$, equals to the age of the tree, whereas the number of growth units $\left(N_{2,3,4}\right)$ on branches depends on the location, age and life span of the axes.

\subsection{Simulation scenarios}

To illustrate the model combination, we simulated a 1-ha initial stand with a density of 6,000 stems per hectare and a height of $2.5 \mathrm{~m}$ at age 10 , which is a common situation for black pine natural regeneration in south-eastern France. Two different management options were compared: the first, named "thinning treatment", consisted in one precommercial thinning at age 15 , followed by three thinnings at ages 45, 60 and 75 , which is close to management recommendations for this species in such relatively good site conditions (Ladier and Rey 2011); the second scenario 
Table 1 An example of output related to branching from PNN for one individual tree. Four whorls are presented here

\begin{tabular}{|c|c|c|c|c|c|c|}
\hline Tree Id & Whorl number from bottom & $B r H t(\mathrm{~m})$ & $D B(\mathrm{~mm})$ & Horiz Extent $(\mathrm{cm})$ & Chord $L(\mathrm{~cm})$ & Ins Ang (grade) \\
\hline 4689 & 9 & 2.28 & 8 & 17 & 20 & 52 \\
\hline 4689 & 9 & 2.28 & 8 & 17 & 20 & 52 \\
\hline 4689 & 9 & 2.28 & 7 & 15 & 18 & 52 \\
\hline 4689 & 9 & 2.28 & 6 & 14 & 16 & 52 \\
\hline 4689 & 8 & 2.03 & 11 & 26 & 31 & 56 \\
\hline 4689 & 7 & 1.77 & 5 & 16 & 17 & 63 \\
\hline 4689 & 7 & 1.77 & 11 & 31 & 36 & 61 \\
\hline 4689 & 7 & 1.77 & 5 & 16 & 17 & 63 \\
\hline 4689 & 7 & 1.77 & 16 & 40 & 53 & 59 \\
\hline 4689 & 7 & 1.77 & 16 & 40 & 53 & 59 \\
\hline 4689 & 6 & 1.52 & 10 & 31 & 34 & 66 \\
\hline 4689 & 6 & 1.52 & 8 & 27 & 29 & 66 \\
\hline
\end{tabular}

was a control without any thinning, but with natural mortality (Table 2).

\section{Model combination}

The outputs from PNN are less detailed than those from GreenLab for individual trees, but some output variables are common for both models. GreenLab was constrained by these common variables. Two adaptations were necessary, the time step and the resolution scale. The time step of PNN simulations was 5 years, whereas it was 1 year for GreenLab: as a first approximation, a linear interpolation was applied. The finest resolution of PNN concerns the

Table 2 Thinning scenarios and corresponding stand density

\begin{tabular}{lll}
\hline Age & \multicolumn{2}{l}{ Stems ha ${ }^{-1}$} \\
\cline { 2 - 3 } & Thinning & Unthinned \\
\hline 15 & $6,000-1,100$ & 6,000 \\
20 & 1,100 & 6,000 \\
25 & 1,095 & 5,960 \\
30 & 1,090 & 5,900 \\
35 & 1,085 & 5,795 \\
40 & 1,075 & 5,650 \\
45 & $1,060-625$ & 5,495 \\
50 & 623 & 5,259 \\
55 & 620 & 5,085 \\
60 & $620-400$ & 4,750 \\
65 & 400 & 4,260 \\
70 & 395 & 3,715 \\
75 & $395-275$ & 3,185 \\
80 & 275 & 2,695 \\
\hline
\end{tabular}

In italics, values after thinning main branches (2nd-order axes) for each individual tree, whereas for GreenLab, it is the organ level; the branching information for each whorl at each time step was computed by PNN, and for GreenLab, additional information was included by considering the botanical information on the development of axes described by Castel et al. (2001).

\subsection{Branch mortality}

Branch mortality was estimated from $H c b$, as shown in Fig. 3a, b for two management scenarios ("thinning treatment" or "unthinned control", see Section 4). At each time step, the highest branch below $H c b$ was the last dead one, whose life span could then be determined by its position (whorl order). By interpolation, the life span of the main branches was computed until the last dead one (Fig. 3c). The life span of higher-order branches was determined empirically as half of the life span of its parent axis, based on botanical observations reported by Castel et al. (2001).

\subsection{Branch number}

The number of main branches (2nd-order axes) along the stem was an output of PNN. The branch number for higher order axes was generated randomly, with a maximum branch number of 3 and 2, respectively, for the 3rd- and 4th-order axes, based on Castel et al. (2001).

\subsection{Growth unit length and diameter}

The length of GUs $(l)$ on the stem and on 2nd-order axes, related to the increment of tree height and of branch length $(L)$, was calculated directly by differential Eq. 1 :

$l_{(i)}=\frac{L_{(i+1)}-L_{(i)}}{t_{(i+1)}-t_{(i)}}$ 
Fig. 3 Dynamics of crown height for the thinning treatment (a) and the unthinned control (b), showing dead and living whorls. c Life span of the main branches for each whorl from the bottom to the top of the stem: the full line represents the thinning treatment and the dashed line the unthinned control a)

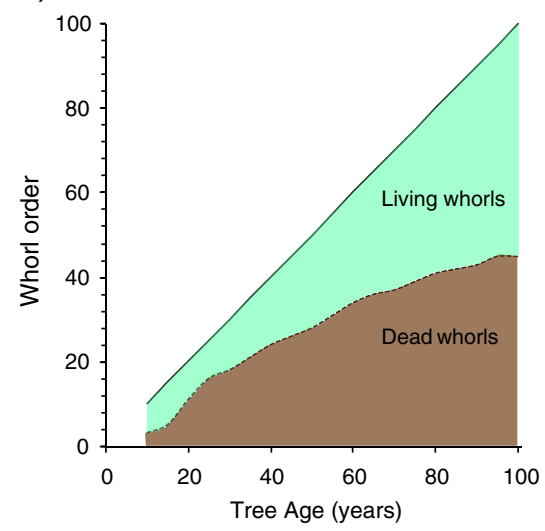

b)

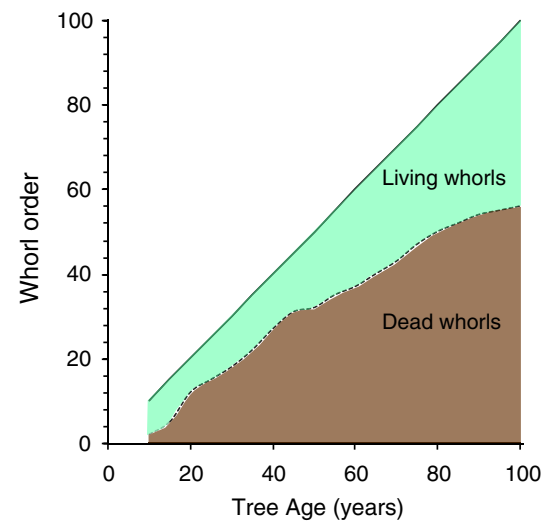

c)

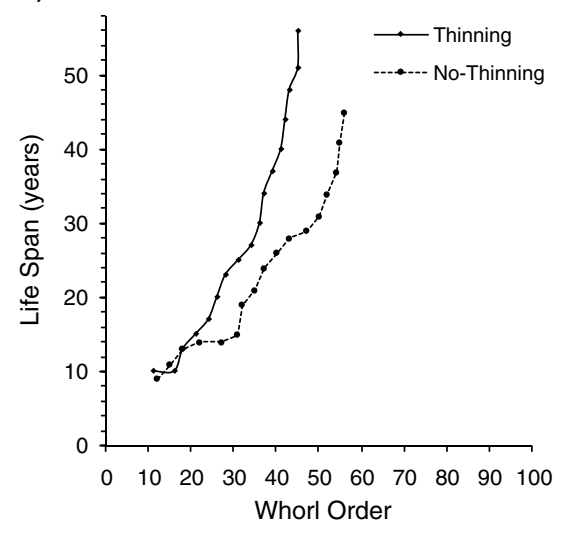

Diameter growth of GUs was simulated by a cone frustrum for which the aperture was estimated from tree height and $d b h$ for the stem (considering no butt swell) and for branches from total branch length $(L)$ and branch base diameter $(D B)$. This way, the diameter of each GU composing the stem or the branches could be estimated by $d b h$ or $D B$, and its distance to the base $(s) . d b h$ and $D B$ at different stages were outputs from PNN, whereas the length of GUs to calculate $s$ was the result of Eq. 1. The length and the diameter of GUs on 3rd- or 4th-order axes were outputs of GreenLab. They were set to be proportional to their corresponding GUs along the parent axes. A ratio of 0.25 was used for diameter, whereas ratios 0.8 and 0.6 , respectively, were used for the length of 3rd- and 4th-order axes, based on Castel et al. (2001).

\subsection{Branch position and bending}

The positions of branches were determined by both insertion angle (between the initial direction of branch and the direction of its parent GU) and phyllotaxy angle. For main branches, insertion angles were PNN outputs (in the branching sub-model of PNN, the insertion angle is related to branch age and branch diameter), whereas a counterclockwise rotation angle of $112.45^{\circ}$ was applied for the phyllotaxy, based on observations by Castel et al. (2001). Insertion angles between $45^{\circ}$ and $60^{\circ}$ were used for 3rdorder axes, insertion angles between $30^{\circ}$ and $45^{\circ}$ were used for 4 th-order axes, while the phyllotaxy angle of $180^{\circ}$ was taken for both.

Branch shape has been estimated in this study, mainly for visualization purposes, based on simple mechanical processes. An elastic curvature of Young's modulus was first used to simulate the bending effect under the weight of the branch in the basal part, as described by Jallas et al. (2009). Then, a re-orientation was calculated to account for the orthotropic growth at the end of the axis, based on the geometrical data (insertion angle and chord length) provided by PNN. The turning angle of each GU was linearly related to an appointed final angle from the vertical.

\subsection{Leaf rendering for visualization purpose}

Similar to the foliage representation of Côté et al. (2011), a symbol representing a bunch of pine needles was applied as the leaves for one growth unit, and the scale was set 
according to growth unit length (see Fig. 4c). A constant needle life span of 3 years was applied.

\section{Simulation results}

Figure 4 shows an example of simulated architecture of the crown of a 30-year-old P. nigra nigra. On the left is the woody architecture with no leaves, showing the form and position of branches. Below is a zoom on the symbol representing the needles for visualization purpose. On the right is the entire crown, including needles. The bottom part of the stem, with no living branches, is not presented here.

Figure 5 shows the architectural development of individual trees according to the two silvicultural scenarios, from ages 10 to 80 years. The scenario for the thinned stand (Fig. 5a) shows the wide crown development and trees with large diameter, whereas the unthinned control scenario (Fig. 5b) shows trees with smaller diameter, high crown base and a small crown, due to the high tree density leading to (tree and) branch mortality.

The simulated stands could then be visualized. The mean characteristics of the stands at age 50 are presented in Table 3. Figure 6 shows (top) the simple output generated by PNN through the Capsis stand visualizer for the thinned stand (left) and the unthinned control (right) at age 50, compared to the output from the present work coupling GreenLab to PNN for the same scenarios: thinned stand (bottom left) and unthinned control (bottom right). The objective was not to represent the entire ecosystem; therefore, no ground vegetation has been added for a more realistic visualization. Computation time to produce a HD $(1,920 \times 1,080$ pixels $)$ image of the unthinned 1-ha stand (5,259 trees) was $25 \mathrm{~min}$ on a 32-bit classical computer, with Intel Core2 duo T9600 processor and $3 \mathrm{G}$ ram.

\section{Discussion}

In the present study, we combined the EFM simulation of tree and stand growth of black pine with an FSPM, in order to link the architectural development of individual trees to the information produced by the EFM. Therefore, individual trees were simulated not only with growth information in relation to silvicultural scenarios but also with consistent botanical information.
Fig. 4 Simulated crown of a 30 -year old $P$. nigra nigra. On the left (a) is the woody architecture with no leaves, on the right (b) is the entire crown, including leaves. The bottom part of the stem, with no living branches, is not presented. The symbol representing the needles for visualization purpose is shown below (c)

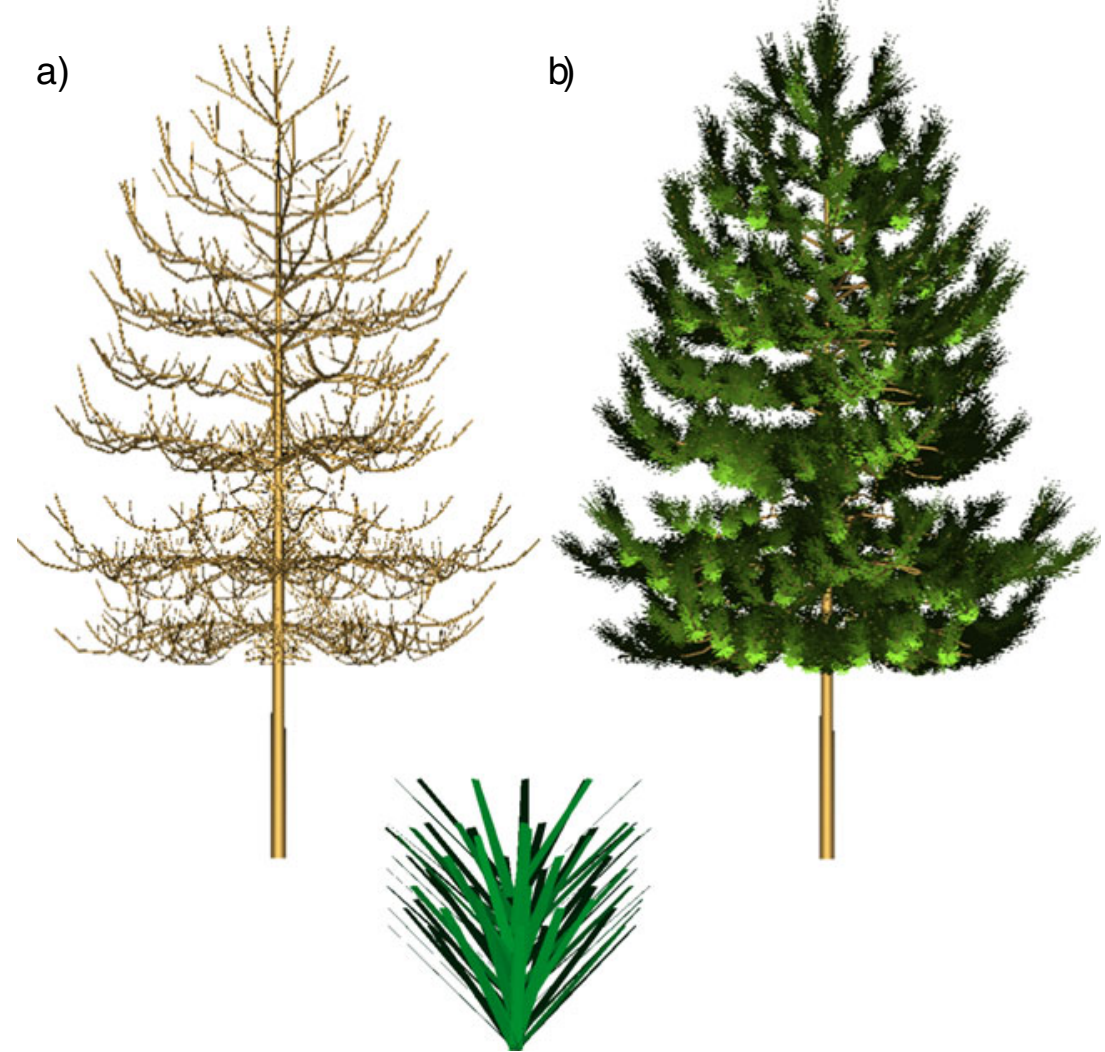

c) 
Fig. 5 Visual representation of black pine dynamics, showing the crown development for the thinning treatment (a) and the unthinned control (b) a)
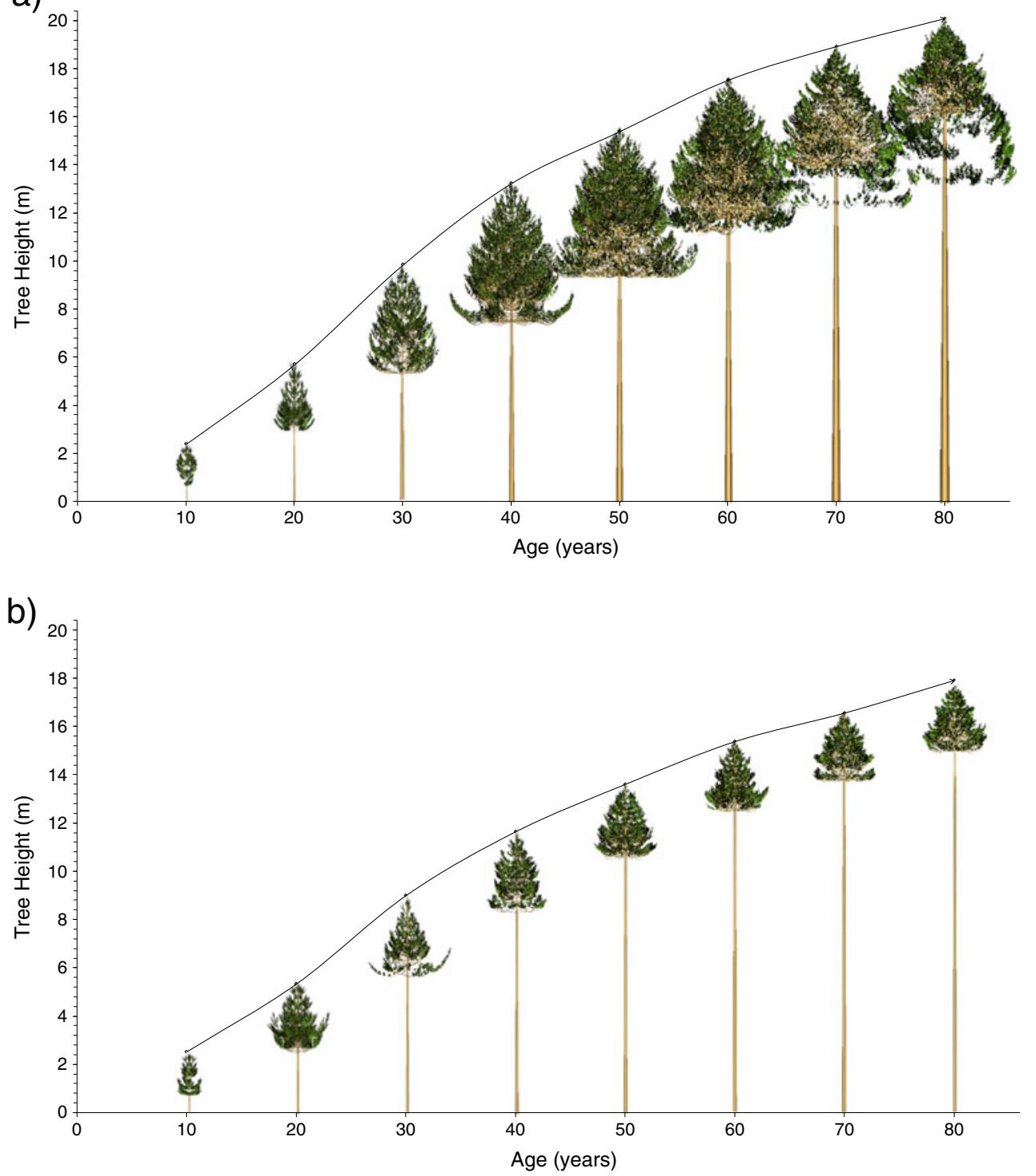

This has been used in the present study to produce a data-driven forest visualization from the EFM simulation. Many different visualization approaches have been developed, as described by Pretzsch et al. (2008). Some can provide interactive real-time visualizations and free perspectives (Lim and Honjo 2003; Griffon et al. 2011). In most approaches, the individual tree development is poorly represented, if at all. Several individual plant simulators have been developed to obtain visually satisfactory tree shapes to be used for example in computer graphics, in which neither detailed botanical knowledge on tree architecture nor precise growth dynamics are necessary. Software like Xfrog (www.xfrog.com, Deussen and Lintermann 2005) and OnyxTree (www.onyxtree.com, Bosanac and Zanchi 2002) for example produce very realistic 3-D tree models, satisfactory for static visualization. Among the few examples, which couple a forest stand simulation model with a visualization software in order to represent tree growth satisfactorily, are TREEVIEW and L-VIS (Pretzsch et al. 2008) or MONTE (Muys et al. 2010). With increasing stakeholders' requirements, it is important to represent individual trees as close as possible to their real architecture and dimensions. In the present work, combining an architectural model and a stand dynamics model produced simulations consistent both with forest growth and with detailed organ-level architecture, leading to a high degree of realism of the represented vegetation, as suggested by Lange (2001). For even better realism, ground vegetation could be added.

Besides visualization, detailed analyses of architecture can be undertaken. For example, Fig. 3 shows the dynamics of crown depth for the thinning treatment (Fig. 3a) and the 
Table 3 Characteristics of the stands at age 50 according to the thinning scenarios. $N=$ Stand Density (stems $\mathrm{ha}^{-1}$ ); $H_{m}=$ average tree height; $H c b=$ height of crown basis; $G=$ stand basal area; $D_{g}=$ quadratic mean diameter

\begin{tabular}{lcc}
\hline & Thinned & Unthinned \\
\hline$N$ & 623 & 5,259 \\
$H_{m}(\mathrm{~m})$ & 14.8 & 14.5 \\
$H c b(\mathrm{~m})$ & 9.6 & 11.4 \\
$G\left(\mathrm{~m}^{2} \mathrm{ha}^{-1}\right)$ & 22.7 & 50.8 \\
$D_{g}(\mathrm{~cm})$ & 21.5 & 11.1 \\
\hline
\end{tabular}

unthinned control (Fig. 3b). Based on these values, Fig. 3c shows how the life span of main branches (2nd order) increased from the bottom of the tree upwards. This is consistent with the "morphogenetic gradient" described by Barthélémy and Caraglio (2007).

Such coupling between an EFM and a FSPM could also be of great interest for estimating biomass production and carbon allocation in the various compartments of the ecosystem. However, for such applications, additional data would be required to better calibrate the dimensions of various organs, in particular the 3rd- and 4th-order axes. The present data were not collected for such an objective, and further field work would be required.

Process-based models generally consider physiological processes, either at the stand level or (for FSPMs) at the individual plant level, but rarely consider the ontogenetic developmental processes which produce the structure of the plants. The objective of the present work was to up-scale individual tree ontogenetic processes at the stand level. A further step will be to integrate not only the architectural component of GreenLab into an EFM but also the physiological processes. Several complementary approaches can be envisaged, such as the hierarchical treatment of multi-scale processes suggested by Mäkelä (2003) and/or using Bayesian methods for combining empirical and process-based models as suggested by Radtke and Robinson (2006).

\section{Conclusion}

In this attempt to combine an architectural model with a stand dynamics model, we used the outputs of PNN to calibrate the 1st- and 2nd-order axes of the architectural component of GreenLab. The PNN model simulated tree and stand growth, according to silvicultural treatment, while GreenLab provided details of the architectural development. In this example, the combined simulation could integrate both the ecological and silvicultural aspects from the stand dynamics model and the structure representation from the architectural model. As a result, tree architecture with a correct time scale was generated, in which it was possible to integrate a thinning scenario and forest growth function from the stand model into the FSPM. Since the two models are independent, the same method can be extended to linkage with other stand models. The first application presented here concerned stand visualization, but this work offers further perspectives for in-depth analyses at the organ level, including carbon allocation.
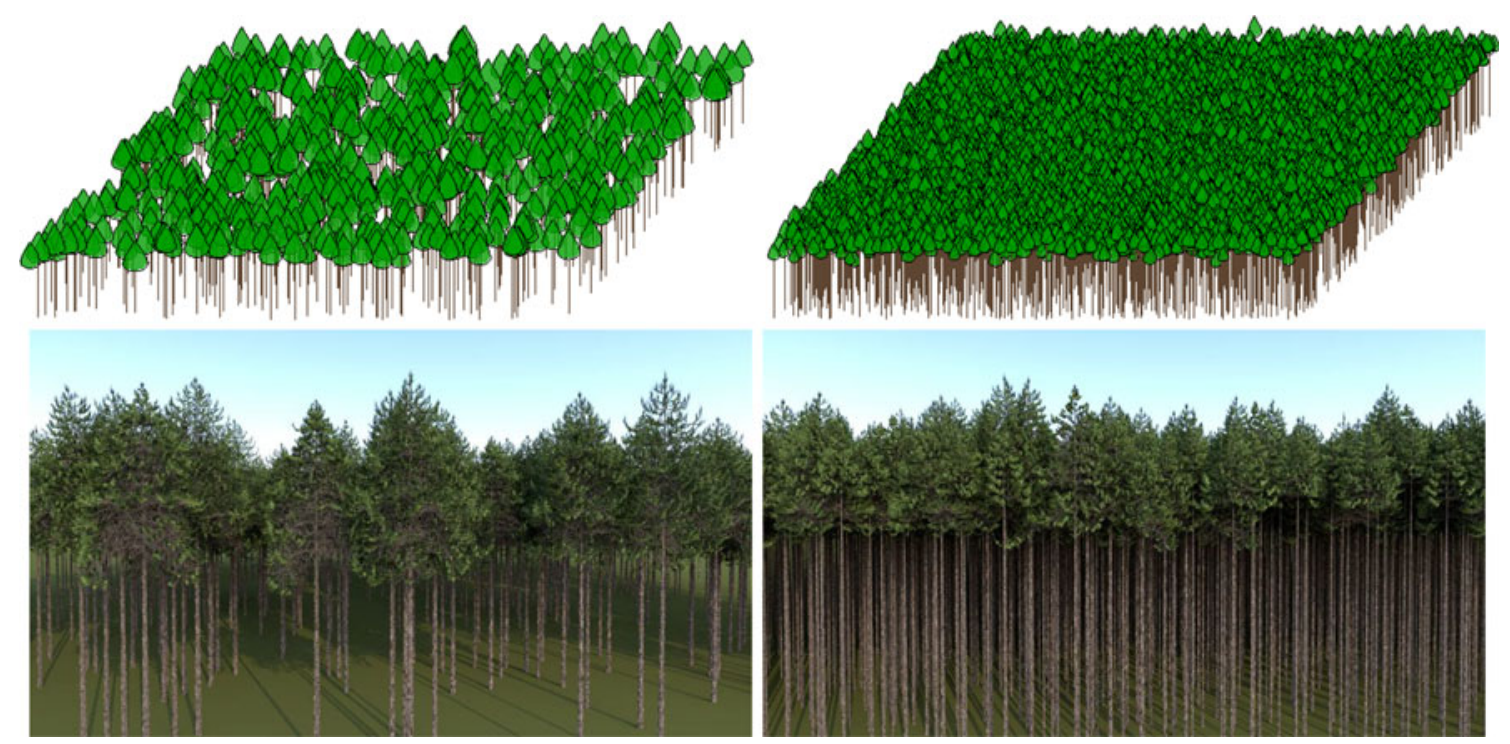

Fig. 6 Visual representation of a black pine stand at age 50: output generated by PNN through the Capsis stand visualizer (top), and output from the present work (bottom). The thinned stands are presented at the

left and the unthinned control at the right. Dead branches are not visualized. See Table 3 for tree and stand characteristics 
Acknowledgements This paper was part of the $\mathrm{PhD}$ project of the first author, which was funded by the China Scholarship Council with the support of CIRAD. The authors are greatly indebted to research technicians of INRA-URFM, non-permanent staff and students, involved in establishing and maintaining plots, measuring surveyed trees, performing stem and branch analyses in the field and hence gathering the data necessary for calibrating the EFM. Thanks are also due to the French National Forest Service (ONF) for allowing us to establish experimental plots in managed stands and to fell trees for stem and branching analyses, to Sébastien Griffon and François de Coligny for their contribution to visualization software development and to two anonymous reviewers for their constructive comments.

\section{References}

Auclair D (2010) Forest and natural ecosystem managers in the landscape-multiscale modelling, challenges and opportunities. In: Fabre JC, Jaeger M, Louchart X, Muller JP (eds) LandMod 2010: International Conference on Integrative Landscape Modelling, Montpellier, France. Available at http://www.symposcience.org

Barthélémy D, Caraglio Y (2007) Plant architecture: a dynamic, multilevel and comprehensive approach to plant form, structure and ontogeny. Ann Bot 99:375-407

Biliouris D, Van der Zande D, Verstraeten WW, Muys B, Coppin P (2009) Assessing the impact of canopy structure simplification in common multilayer models on irradiance absorption estimates of measured and virtually created Fagus silvatica (L.) stands. Remote Sens 1:1009-1027

Bosanac B, Zanchi P (2002) Onyx Tree Conifer User's Manual, version 5.1. Onyx Computing, Cambridge, USA

Brugnach M, Pahl-Wostl C, Lindenschmidt KE et al (2008) Complexity and uncertainty: rethinking the modelling activity. In: Jakeman AJ, Voinov AA, Rizzoli AE, Chen SH (eds) Environmental modelling, software and decision support. Elsevier, Amsterdam, pp 49-68

Castel T, Beaudoin A, Floury N, Le Toan T, Caraglio Y, Barczi JF (2001) Deriving forest canopy parameters for backscatter models using the AMAP architectural plant model. IEEE Trans Geosci Remote Sens 39:571-583

Cescatti A (1997) Modelling the radiative transfer in discontinuous canopies of asymmetric crowns. I. Model structure and algorithms. Ecol Mod 101:263-274

Collin A, Lamorlette A, Bernardin D, Séro-Guillaume O (2011) Modelling of tree crowns with realistic morphological features: new reconstruction methodology based on Iterated Function System tool. Ecol Mod 222:503-513

Côté JF, Fournier RA, Egli R (2011) An architectural model of trees to estimate forest structural attributes using terrestrial LiDAR. Environ Model Softw 26:761-777

de Reffye P (2009) Production végétale et architecture des plantes. Comptes-rendus, Académie d'Agriculture de France. Available at http://www.academie-agriculture.fr/mediatheque/seances/2009/ 20090128resume3_integral.pdf

de Reffye P, Houllier F (1997) Modelling plant growth and architecture: some recent advances and applications to agronomy and forestry. Curr Sci 73:984-992

de Reffye P, Edelin C, Françon J, Jaeger M, Puech C (1988) Plant models faithful to botanical structure and development. Comput Graph 22:151-158

Deussen O, Lintermann B (2005) Digital design of nature: computer generated plants and organics. Springer, Berlin

Dreyfus P (1993) Modelling Austrian black pine response to silvicultural practices in the South East of France. In: Burkhart
HE, Gregoire TG, Smith JL (eds) Proc IUFRO S4.01 conf "Modelling stand response to silvicultural practices". Publ FWS1-93, Virginia Polytech Inst and State Univ, Blacksburg, pp 5-18

Dufour-Kowalski S, Courbaud B, Dreyfus P, Meredieu C, de Coligny F (2011) Capsis: an open software framework and community for forestry modelling. Ann For Sci. doi:10.1007/s13595-011-0140-9

Griffon S, Nespoulous A, Cheylan JP, Marty P, Auclair D (2011) Virtual reality for cultural landscape visualization. Virtual Reality. doi:0.1007/s10055-010-0160-Z

Hallé F, Oldeman RAA, Tomlinson PB (1978) Tropical trees and forests. Springer, Berlin

Jallas E, Sequeira R, Martin P, Turner S, Papajorgji P (2009) Mechanistic virtual modeling: coupling a plant simulation model with a three-dimensional plant architecture component. Environ Model Assess 14:29-45

Kimmins JP, Blanco JA, Seely B, Welham C, Scoullar K (2008) Complexity in modelling forest ecosystems: how much is enough? For Ecol Manage 256:1646-1658

King DA (2005) Linking tree form, allocation and growth with an allometrically explicit model. Ecol Mod 185:77-91

Kohyama T, Canadell J, Ojima DS, Pitelka LF (2005) Forest ecosystems and environments: scaling up from shoot module to watershed. Ecol Res 20:241-242

Ladier J, Rey F (eds) (2011) Guide des Sylvicultures de Montagne pour les Alpes du Sud françaises. ONF-Cemagref-INRA, Paris (in press)

Lange E (2001) The limits of realism: perceptions of virtual landscapes. Landsc Urban Plan 54:163-182

Lim EM, Honjo T (2003) Three-dimensional visualization of forest landscapes by VRML. Landsc Urban Plan 63:175-186

Mäkelä A (2003) Process-based modelling of tree and stand growth: towards a hierarchical treatment of multiscale processes. Can J For Res 33:398-409

Mäkelä A, Landsberg J, Ek AR et al (2000) Process-based models for forest ecosystem management: current state of the art and challenges for practical implementation. Tree Physiol 20:289 298

Mathieu A, Cournède PH, Letort V, Barthélémy D, de Reffye P (2009) A dynamic model of plant growth with interactions between development and functional mechanisms to study plant structural plasticity related to trophic competition. Ann Bot 103:1173-1186

Melson SL, Harmon ME, Fried JS, Domingo JB (2011) Estimates of live-tree carbon stores in the Pacific Northwest are sensitive to model selection. Carbon Balance Manage 6:2

Meredieu C, Caraglio Y, Saint-André L, de Coligny F, Barczi JF (2004) The advantages of coupling stand description from growth models to tree description from architectural models. In: Godin C, Hanan J, Kurth W et al (eds) 4th International Workshop on Functional-Structural Plant Models, 7-11 June 2004, Montpellier, France, pp 243-247

Muys B, Hynynen J, Palahí M et al (2010) Simulation tools for decision support to adaptive forest management in Europe. For Syst 19:86-99

Parsons RA, Mell WE, McCauley P (2011) Linking 3D spatial models of fuels and fire: effects of spatial heterogeneity on fire behavior. Ecol Model 222:679-691

Perttunen J, Sievänen R, Nikinmaa E (1998) LIGNUM: a model combining the structure and the functioning of trees. Ecol Model 108:189-198

Pretzsch H (2009) Forest dynamics, growth and yield. Springer, Berlin

Pretzsch H, Grote R, Reineking B, Rötzer T, Seifert S (2008) Models for forest ecosystem management: a European perspective. Ann Bot 101:1065-1087

Radtke PJ, Robinson AP (2006) A Bayesian strategy for combining predictions from empirical and process-based models. Ecol Model 190:287-298 
Rautiainen M, Mõttus M, Stenberg P, Ervasti S (2008) Crown envelope shape measurements and models. Silva Fennica 42:19-33

Renton M, Kaitaniemi P, Hanan J (2005) Functional-structural plant modelling using a combination of architectural analysis, Lsystems and a canonical model of function. Ecol Model 184:277-298

Sievänen R, Perttunen J, Nikinmaa E, Kaitaniemi P (2008) Toward extension of a single tree functional-structural model of Scots pine to stand level: effect of the canopy of randomly distributed, identical trees on development of tree structure. Funct Plant Biol 35:964-975

Sterck FJ, Schieving F (2007) 3-D growth patterns of trees: effects of carbon economy, meristem activity, and selection. Ecol Monogr $77: 405-420$

Vanclay JK (1994) Modelling forest growth and yield, applications to mixed tropical forests. CAB, Wallingford
Vos J, Evers JB, Buck-Sorlin GH, Andrieu B, Chelle M, de Visser PHB (2010) Functional-structural plant modelling: a new versatile tool in crop science. J Exp Bot 61:2101-2115

Wang X, Song B, Chen J, Zheng D, Crow TR (2006) Visualizing forest landscapes using public data sources. Landsc Urban Plan 75:111-124

Wang F, Kang MZ, Lu Q, Han H, Letort V, Guo Y, de Reffye P, Li B (2010) Calibration of topological development in the procedure of parametric identification: application to the stochastic GreenLab model for Pinus Sylvestris var. Mongolica. In: Li B, Jaeger M, Guo Y (eds) Plant growth modelling, simulation, visualization and applications. IEEE Comput Soc, Los Alamitos, pp 26-33

West GB, Enquist BJ, Brown JH (2009) A general quantitative theory of forest structure and dynamics. PNAS 106:7040-7045

Yan H, Kang MZ, de Reffye P, Dingkuhn M (2004) A dynamic, architectural plant model simulating resource-dependent growth. Ann Bot 93:591-602 